\title{
EFICACIA DEL USO DEL ENJUAGUE DE CLORHEXIDINA DURANTE EL TRATAMIENTO DE ORTODONCIA
}

\author{
${ }^{1}$ Edgar Ibáñez Bolivar, ${ }^{1}$ Liliana Alexandra Aguila V., ${ }^{2}$ Martha Cecilia Mendoza Villamizar \\ ${ }^{1}$ Estudiante de III año de la Especialización en Ortodoncia U. Santo Tomás, \\ ${ }^{2}$ Odontóloga U. Santo Tomás, Docente U. Santo Tomas
}

Autor responsable de correspondencia: Liliana Alexandra Aguilar Villarreal

Dirección de correo electrónico: aguilar_ortodoncia@yahoo.com

\section{RESUMEN}

Objetivo: Determinar la eficacia de la clorhexidina sobre la cantidad de placa dental presente en sujetos adultos, usuarios de aparatología ortodoncica y residentes en el área metropolitana de Bucaramanga que eran atendidos en las clínicas de ortodoncia de la universidad Santo Tomas, durante el segundo semestre del año 2007.

Materiales y métodos: Ensayo clínico controlado realizado con 60 sujetos adultos en tratamiento de ortodoncia. Se estableció el índice de placa OPI (Ortho-Plaque Index) y el índice gingival (GI Index). El grupo intervenido recibió $10 \mathrm{ml}$ de Digluconato de Clorhexidina (0,2 $\%)$, que se utilizó en forma de enjuagues dos veces por día, sin interrupciones por quince días.

Resultados: Los sujetos expuestos a la intervención tenían 2.2 veces más de probabilidad IC (1.6 a 3.3) de tener un índice OPI cuyos valores reflejaban una buena higiene oral.

Conclusiones: Se podría afirmar que la exposición de los sujetos, con tratamiento de ortodoncia, al Digluconato de Clorhexidina (0.2\%), por un periodo de quince días, disminuyó la placa dental significativamente. [Ibañez E, Aguilar LA, Mendoza MC. Eficacia del uso del enjuague de clorhexidina durante el tratamiento de ortodoncia. Revista Ustasalud Odontología 2007; 6: 112 - 122]

Palabras clave: Clorhexidina, Gingivitis, Ortodoncia, Placa dental.

\section{CLOREXIDINE MOUTHWASH EFFECTIVENESS DURING ORTHODONTIC TREATMENT}

\begin{abstract}
Purpose: To evaluate the efficiency of chlorhexidine mouthwash over the amount of bacterian plaque present in adults with orthodontic treatment appliances, living in the Bucaramanga metropolitan area, patients that attend the Santo Tomas University dental clinics, during the second semester of 2007.

Materials and Methods: A controlled clinical essay was performed in 60 adults with orthodontic appliances. It was established the OPI plaque index (Ortho-Plaque index) and the gingival index (GI index). The experimental group received the basic maintenance therapy, chlorhexidine digluconate at $0.2 \%$ to be used as a $10 \mathrm{ml}$ non dilute mouthwash, twice (2) a day for 15 days.

Results: The patients exposed to the intervention had 2.2 times probability (1.6 versus 3.3) of their IC to get the OPI index whose values reflect a good oral hygiene.

Conclusions: The patients with orthodontic appliances who used chlorhexidine digluconate (0.2\%), for fifteen days long had a significant reduction of bacterian plaque.
\end{abstract}

Key words: Chlorhexidine, Gingivitis, Orthodontics, Dental plaque.

Recibido para publicación: 24 de julio de 2007. Aceptado para publicación: 10 de noviembre de 2007.

\section{INTRODUCCIÓN}

El correcto control de la placa dental es un factor primordial de prevención de las principales enfermedades orales (caries dental, gingivitis y periodontitis), que pueden afectar a grupos de riesgo como los usuarios que se encuentran en tratamiento de ortodoncia. La placa dental está presente tanto en individuos sanos como enfermos y corresponde al agente etiológico de las dos enfermedades más pre- 
valentes que afectan las sociedades industrializadas: la caries dental y la enfermedad periodontal. ${ }^{1}$

La relación entre el acumulo de placa y la aparición de gingivitis está demostrada desde los estudios de Löe y colaboradores en $1965 .^{2}$ Bishara señala que en un estudio de 1977, Ericsson y colaboradores encontraron que los aparatos ortodóncicos contribuyen a la presencia de gingivitis que puede degenerar en periodontitis. ${ }^{3}$

Los pacientes sometidos a tratamiento de ortodoncia con aparatología fija tienen mayor riesgo de acumular placa. El alto riesgo es atribuido a la presencia de los alambres, arcos, ligaduras y otros elementos auxiliares ortodóncicos que dificultan las medidas convencionales de higiene oral. ${ }^{3,4}$

Si se permite el crecimiento de la placa bacteriana sin interferencia de medidas de higiene oral, aparecerán algunos cambios cuyos resultados dan lugar al establecimiento de la gingivitis tras dos a tres semanas. En consecuencia, la prevención de la gingivitis, la forma inicial de la enfermedad periodontal, está ampliamente gobernada por la limitación del desarrollo de la placa bacteriana. ${ }^{5}$

A pesar de los avances, en los últimos años, en cuanto a las técnicas y materiales usados en ortodoncia, el desarrollo de la desmineralización y de la caries dental alrededor de la aparatología ortodoncica continúa siendo un problema. Cerca del $50 \%$ de los pacientes con tratamiento de ortodoncia muestran, clínicamente, lesiones de mancha blanca durante el tratamiento que dura aproximadamente dos años. ${ }^{6,7}$ Entre tanto, se ha reportado que la prevalencia de nuevas lesiones del esmalte en pacientes con aparatología fija que usan crema dental con flúor es del $13 \%$ al $75 \%{ }^{8}$

Un tratamiento ortodóncico, en lugar de relacionarse con un alto riesgo de caries debería asociarse, por el contrario, a un riesgo menor ya que es un tratamiento estético y generalmente, voluntario por parte del paciente. ${ }^{9}$ La aparición de lesiones de caries cuestiona el tratamiento ortodóncico en sí mismo. Aunque los ortodoncistas son conscientes de este problema e intentan prevenirlo, las lesiones continúan apareciendo. ${ }^{10}$

Consideraciones de tipo ético empiezan a evidenciarse para el ortodoncista ya que las situaciones clínicas que se pueden derivar de estos eventos son patológicas, no estéticas y potencialmente irreversibles. ${ }^{11}$ Además, se puede llegar a considerar los aspectos legales de la responsabilidad en la supervisión del cuidado bucal de los pacientes a lo largo de todo el tratamiento ortodóncico. ${ }^{12}$

Por lo tanto, es necesario considerar la acciones que en higiene oral se deben adelantar por medio de educación, entrenamiento específico e individual y aplicación de medidas preventivas. ${ }^{9}$

La seda dental es considerada por muchos un método tedioso que necesita demasiado tiempo y que es difícil de usar; la motivación y el cumplimiento a menudo desaparecen con el tiempo. Por estas razones los agentes quimioterapeuticos pueden desempeñar una función importante como ayudante de los métodos mecánicos para la prevención y el tratamiento de las patologías periodontales. ${ }^{13,14}$ Numerosos agentes han sido evaluados para el control de la placa y la reducción o prevención de las enfermedades orales. Los estudios confirman que se puede esperar mayor efecto sobre la reducción de placa y gingivitis con los que contienen clorhexidina, aceites esenciales y triclosan. ${ }^{15,16}$

El Digluconato de Clorhexidina es un agente antimicrobiano tópico que se utiliza en enjuagues bucales para el tratamiento de la gingivitis y de la enfermedad periodontal. Otros usos de la clorhexidina incluyen la profilaxis y el tratamiento de las infecciones de boca, la estomatitis, la estomatitis ulcerativa y la gingivitis ulcerativa necrotizante. Los enjuagues de clorhexidina se utilizan también para tratar y prevenir las mucositis en los pacientes que reciben medicamentos anticancerosos. El espectro antibacteriano de la clorhexidina incluye tanto a bacterias Gram-positivas como Gram negativas, algunos virus como el HIV y algunos hongos, pero sólo es esporicida a elevadas temperaturas. La actividad antiséptica de la clorhexidina es superior a la de la povidona, la espuma de alcohol y el hexaclorofeno. Por todo esto, se ha considerado a la clorhexidina como un antiséptico tópico ideal debido a su persistente actividad sobre la piel con el uso continuo, un efecto muy rápido y una mínima absorción. ${ }^{17}$

De esta manera, ante el panorama descrito por múltiples publicaciones que evidencian la asociación entre la aparatología ortodóncica y el incre- 
mento de la placa bacteriana, se hace necesario desarrollar programas preventivos que refuercen la calidad de los tratamientos y disminuyan los costos tanto biológicos como económicos para el paciente y puedan cumplir con los objetivos estéticos que se buscan. ${ }^{18}$

Al tener en cuenta las consideraciones expuestas anteriormente, se adelantó un ensayo clínico controlado centrado en evaluar el impacto que tendría el uso de la clorhexidina a través del índice de higiene oral OPI (Ortho-Plaque index) y el índice gingival GI (Gingival index), sobre la cantidad de placa dental y la disminución de la inflamación gingival en pacientes con tratamiento de ortodoncia.

Así mismo, este estudio pretendió constituir la base inicial de un protocolo de higiene oral para pacientes con aparatología ortodóncica que ayude a motivar y, por ende, a reducir la patología oral asociada con esta situación clínica.

\section{MATERIALES Y MÉTODOS}

Se realizo un ensayo clínico controlado en el que participaron 60 sujetos adultos con edades entre los 18 y los 40 años, residentes en el área metropolitana de Bucaramanga, en tratamiento de ortodoncia y atendidos en las clínicas odontológicas de la universidad Santo Tomas, durante el segundo semestre del año 2007.

El estudio con una muestra de 30 individuos por grupo permitió observar diferencias con una confianza del $95 \%$ y un poder del $85 \%$.

Previa lectura y firma del consentimiento informado se aplicó una encuesta para conocer los factores que podrían influir en el crecimiento y la consolidación de la placa bacteriana. Posteriormente, se conformaron dos grupos de manera aleatoria, uno de ellos correspondió al grupo intervenido, en tanto que el otro, al grupo control.

Se determinó la cantidad de placa bacteriana y la condición gingival presente en la línea base de los grupos control y de intervención. Para ello, se utilizaron los índices de placa OPI (Ortho-Plaque index) y el índice gingival GI (Gingival index). El OPI usa agentes reveladores de placa; la solución se aplica en la superficie vestibular de los dientes con brackets y luego se evalúa la presencia de placa coloreada con el sistema SI-NO en las tres áreas de la superficie vestibular del diente.

Cada área tiene su nivel de dificultad de acuerdo con la accesibilidad para la limpieza. Los resultados del índice son obtenidos de la siguiente manera: los puntajes resultantes se suman y este valor es dividido por el número de dientes involucrados presentes x 6 x 100-1. El porcentaje obtenido de esta operación corresponde al índice OPI del paciente. Valores entre $0 \%$ y $30 \%$ significan buena higiene oral, entre $31 \%$ y $50 \%$ regular higiene oral, y entre $51 \%$ y $100 \%$ pobre higiene oral. El OrthoPlaque Index (OPI) es fácilmente evaluado durante la cita rutinaria de un paciente; si se repite, puede motivar al paciente a mejorar su higiene. ${ }^{19}$

Se utilizó el índice Gingival de Löe y Silness. Este índice desarrollado en 1963, ayuda a valorar la presencia de gingivitis temprana al incluir la dimensión de la hemorragia al sondaje (Tabla 1). Divide el diente en cuatro áreas para la valoración: papila distovestibular, margen vestibular, papila mesovestibular y todo el margen lingual.

$\mathrm{Al}$ usar este índice, se usa sonda periodontal para determinar la tendencia de hemorragia del tejido; cada una de las cuatro unidades gingivales de un diente recibe un puntaje de 0 a 3. Este es el IG de la unidad. Si los puntajes de las cuatro unidades de un diente se suman y se dividen por 4 , se obtiene el índice gingival del diente. La suma de los puntajes de los grupos de dientes específicos (incisivos, premolares y molares) da el índice gingival del grupo. Finalmente, al sumar los valores de los índices gingivales de todos los dientes y al dividirlo por el número de dientes, se obtiene el índice gingival del paciente. El índice gingival del paciente es un puntaje promedio de todos los dientes presentes. ${ }^{20}$

Este índice es útil en investigaciones epidemiológicas, descriptivas, así como, en epidemiología experimental debido a su gran sensibilidad a los cambios ligeros. Es simple de aplicar y permite a los examinadores calibrarse para minimizar el error interexaminador e intraexaminador. También, es una elección frecuente para el uso de exámenes clínicos controlados con agentes preventivos o terapéuticos. ${ }^{20}$ 
Tabla 1. Calificación para el índice Gingival.

\begin{tabular}{cl}
\hline VALOR & \multicolumn{1}{c}{ CRITERIO } \\
\hline 0 & $\begin{array}{l}\text { Encía normal. } \\
\text { Inflamación media con cambio de color ligero y } \\
1\end{array}$ \\
2 & $\begin{array}{l}\text { edema, sin hemorragia al sondeo. } \\
\text { Inflamación moderada, enrojecimiento, edema } \\
\text { y superficie brillante, hemorragia al sondeo. }\end{array}$ \\
3 & $\begin{array}{l}\text { Inflamación grave con enrojecimiento y edema } \\
\text { marcado, ulceración y tendencia a hemorragia } \\
\text { espontánea. }\end{array}$ \\
\hline
\end{tabular}

De manera previa, se realizó la estandarización del clínico que registró las medidas con un periodoncista, para minimizar la desviación subjetiva en la estimación de los índices.

Posteriormente, los dos grupos recibieron como tratamiento terapia básica de mantenimiento que comprendió: motivación, concientización, enseñanza de técnica de higiene oral. A los dos grupos les fue entregado un estuche que incluía cepillo dental, cepillos interdentales, seda dental y enhebradores.

El grupo de intervención recibió además, digluconato de clorhexidina (CLORHEXOL ${ }^{\circledR}$ enjuague con sabor a menta, frasco por $180 \mathrm{ml}$ con copa dosificadora) al 0,2 \% que fue utilizado en forma de enjuagues sin diluir de $10 \mathrm{ml}$, dos veces por día (después del desayuno y después de la comida) durante 30 segundos, 30 minutos después del cepillado, sin interrupciones por 15 días, a fin de asegurar el cumplimiento del tratamiento.

Se programaron llamadas a los pacientes para recordar el cumplimiento que debían seguir, según las instrucciones recibidas. Se programaron citas a la clínica odontológica para revisar el uso del enjuague.

Los índices se tomaron los días 1, 8, 15 y 30. El primer día, se realizó una profilaxis después de las medidas iniciales del OPI y del IG y se aplicó el OPI (Ortho-Plaque index) para garantizar que éste se encontrara entre el $0 \%$ y $30 \%$, valor que califica como una buena higiene oral. Esta medida ayudo a garantizar la comparabilidad de los grupos.

Las mediciones realizadas fueron registradas denominándose como; T0, T1, T2 y T3, para el OPI e IG0, IG1, IG2 e IG3 para el índice gingival.

Calidad de los datos. Todos los datos fueron revisados en el terreno por los investigadores principales. Éstos se digitaron por duplicado para descartar errores de digitación y fueron validados en el programa
Epi-Info versión 6.04d. Las bases de datos fueron restringidas sólo a los investigadores principales y nunca se identifico en ellas a los participantes.

Análisis estadístico. Se realizó, en las variables continuas, un análisis univariado utilizando para ello promedios con sus respectivos intervalos de confianza al 95\%; para las categóricas o nominales se calcularon porcentajes y sus intervalos de confianza del 95\%. Un análisis bivariado entre la posibles variables confusoras, la intervención ( $\mathrm{Si}$, No) y el resultado de la misma, tuvo como objetivo establecer la magnitud y dirección de las variables y la intervención, en este análisis se utilizó la prueba de $\mathrm{chi}^{2}$ principalmente, y $t$ de student, para las variables continuas. La evaluación del efecto de la clorhexidina se realizó mediante regresión logística, al tener como variable dependiente la disminución de la placa bacteriana (Si, No) y como principal explicatoria la intervención, ajustando por las variables que en el análisis bivariado hayan resultado asociadas. La principal medida de efecto serán Razones de Riesgo Relativas a la Exposición (RR).

\section{RESULTADOS}

Descripción de la población estudiada.

Se estudiaron un total de 60 sujetos, tres de ellos no terminaron el total de mediciones, uno correspondía al grupo intervenido y dos al grupo control. De este total, 31 participantes $(51.7 \%)$ eran mujeres. La edad media fue de 23.4 años (22.2 a 26.4), sin diferencia por sexo $(p=0.581)$. El $48.3 \%$ de los sujetos alcanzaron un grado de escolaridad de universidad, todos los sujetos estudiados eran como mínimo bachilleres. El 35\% de los sujetos reconocieron consumir una dieta rica en fibra dietaria, el $77 \%$, reconoció comer una dieta mixta (ni dura, ni blanda). El 100\% de los sujetos usaba cepillo dental con crema. El 78\% de los sujetos se cepilla tres o más veces al día. La aparatología predominante usada por los pacientes fue de "Brackets + Bandas", un total de $37(61.7 \%)$ la tenían presente al inicio de la intervención. Sólo el $22 \%$ de los sujetos estudiados reconoció usar regularmente seda dental. La principal medida de higiene oral reportada por 29 sujetos $(48 \%)$ fue la de "cepillo dental". Sólo el $7 \%$ de los encuestados usaba regularmente enjuague bucal; otras características de la población estudiada se pueden observar en la tabla 2 .

Comparabilidad de los grupos.

Como se espera en una asignación aleatoria a los grupos intervenido y control, las variables no presentaron diferencias estadísticamente significantes, con excepción de la escolaridad, la cual fue mayor en el grupo intervenido ( $p=0.002$ ) (Tabla 2 ). 
Tabla 2. Análisis univariado y bivariado. Descripción de la población estudiada y comparabilidad de los grupos intervenido y control.

\begin{tabular}{|c|c|c|c|c|}
\hline VARIABLE & TOTAL & INTERVENIDO & CONTROL & VALOR P \\
\hline$\overline{\text { Edad }}$ & $23.4(22.2 \text { a } 26.4)^{*}$ & 22.5 (21.1 a 23.9$)$ & 24.3 (22.3 a 26.4$)$ & 0.139 \\
\hline Género & & & & 0.438 \\
\hline Mujer & & $31(51.7) \dagger$ & $14(46.7)$ & $17(56.7)$ \\
\hline Hombre & & $29(48.3)$ & $16(56.3)$ & $13(48.3)$ \\
\hline Escolaridad & & & & 0.002 \\
\hline Universidad & $29(48.3)$ & $21(70.0)$ & $8(26.7)$ & \\
\hline Tecnólogo & $8(13.3)$ & $1(3.3)$ & $7(23.3)$ & \\
\hline Bachiller & $23(38.3)$ & $8(26.7)$ & $15(50.0)$ & \\
\hline Contenido dieta & & & & 0.087 \\
\hline Fibra & $21(35.0)$ & $11(36.7)$ & $10(33.3)$ & \\
\hline $\mathrm{CHO}$ & $39(65.0)$ & $19(63.3)$ & $20(66.7)$ & \\
\hline Consistencia dieta & & & & 0.361 \\
\hline Dura & & $1(1.67)$ & & $1(3.3)$ \\
\hline Mixta & $46(76.7)$ & $25(85.3)$ & $21(70.0)$ & \\
\hline Blanda & & $13(21.6)$ & $5(16.7)$ & $8(26.7)$ \\
\hline Tipo de aparatología $\neq$ & & & & 0.437 \\
\hline Brackets & $13(21.7)$ & $8(26.7)$ & $5(16.7)$ & \\
\hline Brackets +1 & $37(61.7)$ & $18(60.0)$ & $19(63.3)$ & \\
\hline Brackets +2 & $9(15.0)$ & $3(10.0)$ & $6(20.0)$ & \\
\hline Brackets +3 & $1(1.6)$ & $1(3.3)$ & & \\
\hline \multicolumn{5}{|l|}{ Uso de cepillo dental } \\
\hline $\mathrm{Si}$ & $60(100.0)$ & $30(100.0)$ & $30(100.0)$ & \\
\hline \multicolumn{5}{|l|}{ Uso de crema dental } \\
\hline $\mathrm{Si}$ & $60(100.0)$ & $30(100.0)$ & $30(100.0)$ & \\
\hline Frecuencia de uso de crema dental & & & & 0.070 \\
\hline Tres o +/día & $47(78.3)$ & & $27(90.0)$ & $20(66.7)$ \\
\hline Dos/día & $11(18.3)$ & $3(10.0)$ & $8(26.7)$ & \\
\hline Una/día & $2(3.4)$ & & $2(6.6)$ & \\
\hline \multicolumn{5}{|l|}{ Frecuencia de cepillado } \\
\hline Tres o +/día & $47(78.3)$ & $27(90.0)$ & $20(66.7)$ & \\
\hline Dos/día & & $11(18.3)$ & $3(10.0)$ & $8(26.7)$ \\
\hline Una/día & $2(3.4)$ & & & $2(6.6)$ \\
\hline Uso de seda dental & & & & 0.347 \\
\hline $\mathrm{Si}$ & $13(21.7)$ & $5(16.7)$ & $8(26.7)$ & \\
\hline No & $47(78.3)$ & $25(83.3)$ & $22(78.3)$ & \\
\hline Frecuencia de uso de seda dental & & & & 0.319 \\
\hline Dos o +/día & $11(18.3)$ & $5(16.7)$ & $6(20.0)$ & \\
\hline Una/día & $2(3.3)$ & & $2(6.7)$ & \\
\hline Nunca & & $47(78.4)$ & $25(83.3)$ & $22(73.3)$ \\
\hline Medidas de higiene oral & & & & 0.475 \\
\hline \multicolumn{5}{|l|}{ Cepillo+1 } \\
\hline Cepillo +2 & $7(11.7)$ & $5(16.7)$ & $2(6.7)$ & \\
\hline Cepillo +3 & $24(40.0)$ & $11(36.7)$ & $13(43.3)$ & \\
\hline Cepillo +4 & $29(48.3)$ & $14(46.6)$ & $15(50.0)$ & \\
\hline PH de la saliva & & & & 0.150 \\
\hline Neutro & $2(3.3)$ & $2(6.7)$ & & \\
\hline Básico & $58(96.7)$ & $28(93.3)$ & $30(100.0)$ & \\
\hline Uso de enjuague bucal & & & & 0.301 \\
\hline $\mathrm{Si}$ & & $4(6.7)$ & $3(10.0)$ & $1(3.3)$ \\
\hline No & $56(93.3)$ & $27(90.0)$ & $29(96.7)$ & \\
\hline
\end{tabular}

*. Promedio e intervalo de confianza del 95\%. †. Frecuencia $\{\%\}$. キ. Brackets, Brackets +1; Brackets + bandas. Brackets +2 ; Brackets + bandas + aparatología adicional en un solo maxilar, Brackets +3 ; Brackets + bandas + aparatología adicional en los dos maxilares. |. Cepillo+1; Cepillo dental + cepillo interdental + seda Dental + enjuague. Cepillo+2; Cepillo dental + cepillo interdental + seda Dental. Cepillo+3; Cepillo dental + cepillo interdental. Cepillo+4; Cepillo dental. 
Evaluación de la intervención.

La intervención fue evaluada de tres maneras independientes. La primera de ella a través de la medición del índice de higiene oral (OPI), en la línea de base, a los ocho, quince y treinta días post inicio de la intervención, entre la última y la penúltima medición de OPI, no hubo intervención. La tabla 3, muestra como este índice mejora substancialmente, al pasar de la calificación de "bueno" del 3.3\% en la línea de base a $29 \%$ a final de la intervención, y a $53 \%$ quince días después de finalizada la misma. El impacto positivo de la intervención es indiscutible puesto que las diferencias de estas proporciones frente a la línea de base son estadísticamente significativas ( $p=0.006$ al final de a intervención).
La segunda forma como se evaluó la intervención fue a través del índice gingival (IG), al igual que el OPI, éste se midió en la línea de base, a los ocho, quince y treinta días post inicio de la intervención; entre la última y la penúltima medición del índice gingival, no hubo intervención. La tabla 4, muestra como la calificación de "normal" para la encía pasa de $23 \%$ en la línea de base a $63 \%$ al final de la intervención y a $83 \%$, quince días post finalizada la intervención.

La tercera forma en que se evaluó la intervención fue mediante un modelo multivariado, que utilizó regresión binomial para calcular Razones de Prevalencia (RP), entre el grupo expuesto a Dicoglunato de Clorhexidina (0.2\%) y el control, al ajustar las

Tabla 3. Valores del OPI en la población estudiada, grupo intervenido y control.

\begin{tabular}{|c|c|c|c|c|}
\hline VARIABLE & TOTAL & INTERVENIDO & CONTROL & VALOR P \\
\hline \multicolumn{4}{|c|}{ Índice de higiene oral (OPI) en la línea de base. } & 0.353 \\
\hline Bueno & $2(3.3)$ & $1(3.3)$ & $1(3.3)$ & \\
\hline Regular & $17(28.3)$ & $11(36.7)$ & $6(20.0)$ & \\
\hline Pobre & $41(61.4)$ & $18(60.0)$ & $23(76.7)$ & \\
\hline \multicolumn{4}{|c|}{ Índice de higiene oral (OPI) a los ocho días post inicio de la intervención. } & 0.090 \\
\hline Bueno & $7(11.7)$ & $6(20.0)$ & $1(3.3)$ & \\
\hline Regular & $23(38.3)$ & $12(40.0)$ & $11(36.7)$ & \\
\hline Pobre & $30(50.0)$ & $12(40.0)$ & $18(60.0)$ & \\
\hline \multicolumn{4}{|c|}{ Índice de higiene oral (OPI) a los quince días post inicio de la intervención. } & 0.006 \\
\hline Bueno & $17(28.8)$ & $13(43.3)$ & $4(13.8)$ & \\
\hline Regular & $33(55.9)$ & $16(53.3)$ & $17(58.6)$ & \\
\hline Pobre & $9(12.5)$ & $1(3.3)$ & $8(27.6)$ & \\
\hline \multicolumn{4}{|c|}{ Índice de higiene oral (OPI) a los treinta días post inicio de la intervención. } & 0.077 \\
\hline Bueno & $30(52.6)$ & $19(65.5)$ & $11(39.3)$ & \\
\hline Regular & 25 (43.9) & $10(34.5)$ & $15(53.6)$ & \\
\hline Pobre & $2(3.5)$ & & $2(7.1)$ & \\
\hline
\end{tabular}

Tabla 4. Índice gingival en la población estudiada, grupo intervenido y control.

\begin{tabular}{|c|c|c|c|c|}
\hline VARIABLE & TOTAL & INTERVENIDO & CONTROL & VALOR P \\
\hline \multicolumn{4}{|c|}{ Índice gingival en la línea de base. } & 0.053 \\
\hline Normal & $8(13.3)$ & $7(23.3)$ & $1(3.3)$ & \\
\hline Inf. Leve & $37(61.7)$ & $15(50.0)$ & $22(73.3)$ & \\
\hline Inf. Mod & $15(25.0)$ & $8(26.7)$ & $7(23.4)$ & \\
\hline \multicolumn{4}{|c|}{ Índice gingival a los ocho días post inicio de la intervención. } & 0.022 \\
\hline Normal & $9(15.0)$ & $8(26.7)$ & $1(3.3)$ & \\
\hline Inf. Leve & $43(71.7)$ & $20(66.7)$ & $23(76.7)$ & \\
\hline Inf. Mod & $8(13.3)$ & $2(6.6)$ & $6(20.0)$ & \\
\hline \multicolumn{4}{|c|}{ Índice gingival a los quince días post inicio de la intervención. } & 0.003 \\
\hline Normal & $25(42.4)$ & $19(63.3)$ & $6(20.7)$ & \\
\hline Inf. Leve & $32(54.2)$ & $11(36.7)$ & $21(72.4)$ & \\
\hline Inf. Mod & $2(3.4)$ & & $2(6.9)$ & \\
\hline \multicolumn{4}{|c|}{ Índice gingival a los treinta días post inicio de la intervención. } & 0.000 \\
\hline Normal & $33(57.9)$ & $24(82.8)$ & $9(32.1)$ & \\
\hline Inf. Leve & $24(42.1)$ & $5(17.2)$ & $19(67.9)$ & \\
\hline
\end{tabular}


Tabla 5. Razón de Prevalencia (RP) para la intervención, ajustada por variables confusoras; edad, género, escolaridad, contenido de la dieta y ph de la saliva.

\begin{tabular}{|c|c|c|}
\hline VARIABLES & $\begin{array}{c}\text { RP } \\
\text { IC (95\%) }\end{array}$ & VALOR P \\
\hline Expuesto a Dicoglunato de Clorhexidina (0.2\%) & & 0.000 \\
\hline No & $1.0 \dagger$ & \\
\hline $\mathrm{Si}$ & 2.2 (1.6 a 3.3$)$ & \\
\hline Edad & $1.0 \dagger$ & 0.000 \\
\hline$<=23$ años & $1.2(1.2$ a 1.2$)$ & \\
\hline$>23$ años & & \\
\hline Género & & 0.000 \\
\hline Mujer & $1.0 \dagger$ & \\
\hline Hombre & $1.4(1.4$ a 1.4$)$ & \\
\hline Escolaridad & & 0.000 \\
\hline Universitario & $1.0 \dagger$ & \\
\hline Técnico/tecnólogo & $0.8(0.8$ a 0.8$)$ & \\
\hline Bachiller & $1.03(1.0$ a 1.1$)$ & \\
\hline Contenido de la dieta & & 0.000 \\
\hline Rica en carbohidratos & $1.0 \dagger$ & \\
\hline Rica en fibra dietaria & $1.4(1.4$ a 1.4$)$ & \\
\hline pH de la saliva & & 0.521 \\
\hline Neutro & $1.0 \dagger$ & \\
\hline Básico & $1.6(0.4$ a 7.7$)$ & \\
\hline
\end{tabular}

Variable dependiente: OPI: 0 = Bueno, 1 = Regular ó malo.

${ }^{*}$ Razones de prevalencia e intervalos de confianza del 95\%. $\dagger$, Categoría de base.

Tabla 6. Evaluación de la sustantividad. Higiene oral según el índice OPI. (\%)

\begin{tabular}{|c|c|c|c|c|}
\hline & \multicolumn{4}{|c|}{ OPI a los 30 días } \\
\hline & Bueno & Regular & Pobre & Total \\
\hline \multicolumn{5}{|c|}{ OPI a los 15 días } \\
\hline Bueno & $17(100)$ & --- & --- & $17(29.8)$ \\
\hline Regular & 13(41.9) & $17(54.8)$ & $1(3)$ & $31(54.4)$ \\
\hline Pobre & --- & $8(88.8)$ & $1(11.1)$ & $9(15.8)$ \\
\hline Total & $30(52.6)$ & $25(43.9)$ & $2(3.5)$ & $57(100)$ \\
\hline
\end{tabular}

Tabla 7. Evaluación de la sustantividad. Higiene oral según el índice gingival. (\%)

\begin{tabular}{lcccc}
\hline & & \multicolumn{2}{c}{ Índice Gingival a los 30 días } \\
Inf. Moderada & Total \\
\hline $\begin{array}{l}\text { IG a los 15 días } \\
\text { Normal }\end{array}$ & $25(100)$ & --- & -- & $25(43.9)$ \\
Leve & $8(26.7)$ & $22(73.3)$ & & $30(52.6)$ \\
Inf. Moderada & $2(100)$ & --- & -- & $2(3.5)$ \\
Total & $33(57.9)$ & $24(42.1)$ & $\ldots$ & 57 \\
\hline
\end{tabular}

$\operatorname{chi}^{2}(2)=32.93$. Valor $\mathrm{p}=0.000 . n$ en IG a los 15 días: $59 . n$ en IG a los 30 días: 57. 
posibles variables confusoras, en particular la escolaridad, la única variable que presentó imbalance al comienzo del ensayo. El resultado se puede observar en la tabla 5 , en ella se evidencia que los sujetos expuestos a la intervención tienen 2.2 más veces de probabilidad IC (1.6 a 3.3) de tener un índice OPI calificado como "bueno".

Variables asociadas a un índice OPI calificado como "bueno".

La tabla 5, además, evidencia que tener 24 o más años de edad, ser hombre, una mayor escolaridad, una dieta rica en fibra y pH salival básico, actúan como factores protectores en presencia de Dicoglunato de Clorhexidina $(0.2 \%)$ para tener un índice OPI calificado como "bueno".

\section{Evaluación de la sustantividad.}

La sustantividad se evaluó al probar la calificación de los índice gingival y OPI al finalizar la intervención y 15 días después de finalizada la misma. Las tablas 6 y 7 muestran de manera contundente como el efecto sobre la disminución de la placa bacteriana permanece, y sigue en descenso aún quince días después de no exponer los pacientes al Dicoglunato de Clorhexidina (0.2\%). La calificación "bueno" para OPI aumento de $30 \%$ a $53 \%$, y la calificación de "encía normal" según el índice gingival paso de $44 \%$ a $58 \%$. Las diferencias a favor de la disminución de la placa bacteriana para ambos índices son estadísticamente significativas $(\mathrm{p}=0.000)$.

Los resultados mostrados en las tablas 2 a 7 permitieron afirmar que la exposición durante quince días a Dicoglunato de Clorhexidina (0.2\%), permite disminuir la placa bacteriana significativamente, incluso aún después de terminar la exposición -quince días post finalización de la intervención en este ensayo-.

\section{DISCUSIÓN}

Este estudio aborda una temática que sistemáticamente se desconoce por considerarse básica, pero que es fundamental a la hora de hablar de atención integral, de ética, y de obtener resultados clínicos. La ortodoncia como procedimiento odontológico especializado debe garantizar resultados íntegros a los pacientes que deciden iniciarlo. Por lo tanto, deben orientarse todas las medidas que estén relacionadas con la preservación de unas adecuadas condiciones de salud oral integral.

Los pacientes sometidos a tratamiento de ortodoncia tienen mayor riesgo de acumular placa. El alto riesgo se atribuye a la presencia de diversos tipos de aparatos básicos y otros elementos auxiliares ortodóncicos que dificultan las medidas convencionales de higiene oral.,4

La literatura ha demostrado que los tratamientos de ortodoncia incrementan la acumulación de placa y la colonización bacteriana por lo que resultan afectados los tejidos periodontales y dentarios. ${ }^{21-25}$ Si se permite el crecimiento de esta placa aparecerán algunos cambios cuyos resultados dan lugar al establecimiento de la gingivitis tras dos a tres semanas.

Una forma de evidenciar el desarrollo, presencia y crecimiento de esta biopeliculas es a través del uso de índices que permiten definir la presencia de placa. Éstos deben garantizar la obtención de la información del estado del paciente de una manera rápida, segura y práctica. El OPI descrito por Heintze y desarrollado en 1989 por Declerck, ${ }^{19}$ ha sido de gran ayuda en este estudio como lo ha sido en otros..$^{18}$ No obstante, algunas otras investigaciones han hecho uso del índice para placa de Silness y Löe, que ha mostrado ser lo suficientemente confiable. ${ }^{14}$

$\mathrm{Al}$ inicio de este estudio, el $61.4 \%$ del total de los pacientes que intervinieron en él, presentaban índices que reflejaban una muy pobre higiene oral, y el $\mathbf{8 6 . 7 \%}$ de ellos presentaba inflamación gingival de leve a moderada. Varios autores han demostrado que en pacientes con tratamientos de ortodoncia hay una correlación casi lineal entre la acumulación de placa y el desarrollo de lesiones de caries. ${ }^{26,27}$

El 78.3\% de los pacientes del total de la muestra presentaba brackets y bandas; Hamp y colaboradores sugieren que los pacientes con aparatología ortodóncica fija (brackets y bandas) requieren métodos reforzados en la higiene oral personal y procedimientos profilácticos adicionales por parte del especialista. ${ }^{28}$ 
Muchos agentes han sido evaluados como coadyuvantes en la mejoría de las condiciones de higiene oral al disminuir la presencia de placa y, por tanto, la presencia de las enfermedades orales. Aquellos que contienen clorhexidina, aceites esenciales y triclosan, han reportado mejores efectos en el control de la placa bacteriana. ${ }^{15,16}$

En este estudio, se evaluó la eficacia del uso de un enjuague digluconato de clorhexidina al $0.2 \%$ en el control de la placa bacteriana y en la disminución de la inflamación gingival en pacientes con tratamento de ortodoncia y que asistían a las clínicas odontológicas de la Universidad Santo Tomás, en Bucaramanga. Las mediciones fueron realizadas en un periodo de treinta días.

El diseño del formato para la recolección de información recogia datos relacionados con variables que pueden afectar o facilitar la eficacia del enjuague objeto del estudio. Es importante señalar que la población de ambos grupos, objeto de este estudio fue distribuida por asignación aleatoria. Como se espera en una asignación de estas características, las variables no presentan diferencias estadísticamente significantes, con excepción de la escolaridad, que aun cuando mayor en el grupo intervenido no representa un desequilibrio real sobre el resultado final del ensayo. La información recolectada con respecto al grado de escolaridad muestra que los participantes en el estudio presentan como mínimo formación como bachilleres. A pesar de la significancia estadística se tiene que considerar el concepto de la significancia social y biológica. Esto es, que a pesar de la diferencia en los números no es fácil atribuir el resultado obtenido a una variable, en este caso, la escolaridad, ya que los involucrados en el estudio, alcanzan según los registros de recolección de información, un nivel de formación en el que se puede concluir que están en capacidad de recibir y seguir instrucciones. Otra consideración importante se relaciona con el hecho de que las muestras pequeñas pueden conducir a que no se logre el balance esperado en la distribución aleatoria.

Los resultados de este estudio indican que el uso de un enjuague bucal que contenga Dicoglunato de Clorhexidina $(0.2 \%)$ es efectivo en la reducción de la placa y en la disminución de los niveles de gingivitis durante el tiempo del ensayo clínico (30 días). Estos resultados concuerdan con estudios previos en los que el Digluconato de Clorhexidina fue usado, en pacientes bajo tratamiento ortodóncico. ${ }^{29}$

Esta significativa reducción encontrada en los pacientes intervenidos puede ser explicada por la acción farmacológica de la clorhexidina y una mayor frecuencia de medidas profilácticas, en general. El análisis de sustantividad considerado entre los periodos de medición T2 - T3 e IG2 - IG3 podría explicarse con de acuerdo con el concepto anterior; sin embargo, es también importante señalar que la persona después de la intervención puede desarrollar procesos cognitivos que sumados al proceso mecánico de la intervención ayudaría a obtener unas mejores condiciones de higiene bucal, reflejadas en una disminución en los valores del OPI y del IG. Es así como al final del estudio, el 65.5\% (19) de los participantes del grupo intervenido se encontraban en la categoría de buena higiene oral, el $34.5 \%$ (10) de los participantes en la categoría de regular higiene oral y ninguno en la categoría de pobre higiene oral.

En lo que tiene que ver con el índice gingival, los valores disminuyeron al final de estudio tanto en el grupo control como en el grupo intervenido; ninguno de los participantes presentaba sangrado gingival lo que puede explicarse por la acción farmacológica de la clorhexidina y por la motivación resultado del contacto de los investigadores con los voluntarios, esto pudo reforzar la responsabilidad de los pacientes con su propia salud oral al reflejarse un cambio de actitud. Algunos estudios lo confirman. ${ }^{19,30}$

Este trabajo demostró que los enjuagues bucales con clorhexidina garantizan un efectivo control de la placa bacteriana (grupo intervenido); los resultados fueron superiores a los obtenidos sólo con el uso de medidas mecánicas (grupo control). Así mismo, la concentración usada $(0.2 \%)$ permitió obtener unos efectos que se pueden calificar como rápidos. Además confirman lo señalado en algunos trabajos en lo que tiene que ver con las propiedades ideales de los agentes antiplaca, y que se resumen en la sustantividad, reducción de los agentes causantes de la inflamación y facilidad para su utilización. ${ }^{31}$ Sin embargo, otros estudios muestran resultados igualmente favorables 
en concentraciones menores, tales como $0.12 \%$, en periodos de tiempo de 90 días. ${ }^{14}$

Los efectos adversos reportados por los voluntarios del grupo intervenido correspondieron al cambio de sabor en los alimentos y en la textura del dorso de la lengua; no se evidenciaron cambios en el color de los dientes.

Son varios los artículos que incluyen propuestas de medidas preventivas que contienen como principio activo la clorhexidina, y que según se señaló en los resultados obtenidos permiten mejorías sustanciales. Las presentaciones son diversas y contemplan opciones tales como enjuagues bucales, geles o dentífricos, cuyo efecto depende en mayor medida de la cooperación del paciente. ${ }^{32,33}$ Adicionalmente, de acuerdo con algunos reportes en la literatura, medidas adicionales como el uso de cepillos eléctricos con acción rotatoria en pacientes con tratamiento de ortodoncia remueven más placa y reducen la gingivitis más efectivamente que el cepillado manual. ${ }^{34,35}$

Es necesario desarrollar programas preventivos que refuercen la calidad de los tratamientos y disminuyan los costos tanto biológicos como económicos para el paciente y puedan cumplir con los objetivos estéticos que cada vez son más frecuentemente buscados por los pacientes. ${ }^{35}$ Por lo tanto y teniendo en cuenta los resultados obtenidos, se considera pertinente recomendar el uso de intervenciones adicionales preventivas, tales como controles de placa, sondeos gingivales y aplicaciones periódicas de enjuagues con clorhexidina al $0.2 \%$, medidas que harían parte de un protocolo de prevención en pacientes con aparatología ortodóncica. Hay que tener presente que la motivación surge en buena medida del contacto de un profesional comprometido que refuerce la responsabilidad del paciente por su salud.

\section{CONCLUSIONES}

- El 50\% de los voluntarios del grupo intervenido mejoró al reducir sus niveles de placa bacteriana.

- El enjuague con Digluconato de Clorhexidina al $0.2 \%$ en combinación con la remoción mecánica de la placa bacteriana es un tratamiento importante para el control de los niveles de placa, inflamación y sangrado gingival.

- La diferencia de los promedios del índice gingival y el OPI entre las mediciones iniciales y finales, al mes, entre los dos grupos, fue significativa.

- Es necesario tomar medidas adicionales preventivas tales como aplicaciones periódicas de enjuagues de clorhexidina al $0.2 \%$, controles de placa y sondeos gingivales para evitar problemas periodontales y lesiones de caries dental en pacientes con tratamiento de ortodoncia.

\section{BIBLIOGRAFÍA}

1. Lindhe J, Theilade J. Dental Plaque and Dental Calculus. Clinical Periodontology, $2^{\text {nd }}$. Ed. Munksgaard, Copenhagen, 1989. p. $92-128$.

2. Löe $H$, Theilade $E$, Jensen $S B$. Experimental gingivitis in man. J Periodontol 1965; 36: 177- 187.

3. Bishara S. Ortodoncia. Mc Graw Hill. p. 478.

4. Derks A, Katsaros C, Frencken JE, van't Hof MA, Kuijpers-Jagtman AM. Caries-inhibiting effect of preventive measures during orthodontic treatment. Caries Res 2004; 38: 413 - 420 .

5. Bernimoulin JP. Recent concepts in plaque formation. J Clin Periodontology 2003; 30: 7 - 9.

6. Basdra EK, Huber H, Komposch G. Fluoride release from orthodontic bonding agents alters the enamel surface and inhibits enamel demineralization in vitro. Am J Orthod Dentofacial Orthop 1996; 109: $466-472$.

7. Øgaard B, Rølla G, Arends J. Orthodontic appliances and enamel demineralization. Part 1. Lesion development. Am J Orthod Dentofacial Orthop 1988; 94: 68 - 73.

8. Derks A, Kuijpers-Jagtman Am, Frencken Je, Van't Hof $\mathrm{M}$, Katsarose C. Caries preventive measures used in orthodontic practices: An evidence-based decision? Am J Orthod Dentofacial Orthop 2007; 132: 165 - 170.

9. Baysan A, Lynch E. Effect of ozone on the oral microbiota and clinical severity of primary root caries. Am J Dent 2004; 17: 56 - 60.

10. Todd MA, Staley RN, Kanellis MJ, Donly KJ, Wefel JS. Effect of a fluoride varnish on demineralization adjacent to orthodontic brackets. Am J Orthod Dentofacial Orthop 1999; 116: 159 - 167.

11. Burkland G. Hygiene and the orthodontic patient. J Clinic Orthod 1999; 33: 443 - 446.

12. Machen D. Legal aspects of orthodontic practice: risk management Concepts. Am J Orthod Dentofacial Orthop 1991; 29: 594 - 598. 
13. Santos A. Evidence -based control of plaque and gingivitis. J Clin Periodontology 2003; 30: 13 - 16.

14. Brightman LJ, Terezhalmy GT, Greenwell H, Jacobs M, Enlow DH. The effects of a $0.12 \%$ chlorhexidine gluconate mouth rinse on orthodontic patients aged 11 through 17 with established gingivitis. Am J Orthod Dentofacial Orthop 1991; 100: 324 - 329.

15. Øgaard B, Afzelius Alm A, Larsson E, Adolfsson U. A prospective, randomized clinical study on the effects of an amine fl uoride/stannous fluoride toothpaste/ mouthrinse on plaque, gingivitis and initial caries lesion development in orthodontic patients. Eur J Orthod 2006; $28: 8$ - 12 .

16. Van Rijkom HM, Truin GJ, Vant'hof MA. A meta-analysis of clinical studies on the caries inhibiting effect of chlorhexidine treatment. J Dent Res 1996; 75: 790 - 795.

17. Charles CH, Mostler KM, Bartels LL, Mankodi SM. Comparative antiplaque and antigingivitis effectiveness of a chlorhexidine and an essential oil mouthrinse: 6-month clinical trial. J Clin Periodontol 2004; 31: 878 -884 .

18. Martignon S, Ekstrand KR, Lemos MI, Lozano MP, Higuera C, Mora G, Bautista MP. Estado de salud oral en pacientes con tratamiento de ortodoncia: examen visual usando los criterios diagnósticos ICDAS y OPI. Universidad El Bosque, Bogotá, Colombia; University of Copenhagen, Denmark. Memorias XVII Encuentro Nacional de Investigación Odontológica. ACFO 14,15 y 16 de septiembre de 2006. Universidad Santo Tomás. Bucaramanga.

19. Heintze SD, Jost-Brinkmann PG, Finke CH, Miethke RR. Oral health for the orthodontic patient. Illinois: Quintessence Publishing Co, Inc, 1999.

20. Katz S, McDonald JL, Stookey GK. Odontologia Preventiva en Acción. Ed. Médica Panamericana 1982.

21. Boersma JG, van der Veen MH, Lagerweij MD, Bokhout B, Prahl-Andersen B. Caries prevalence measured with QLF after treatment with fixed orthodontic appliances: influencing factors. Caries Res 2005; 39: 41 - 47.

22. Corbett JA, Brown LR, Keene HJ, Horton IM. Comparison of Streptococcus mutans concentrations in non-banded and banded orthodontic patients. J Dent Res 1981; 60: 1936 - 1942.

23. Scheie Aa, Arneberg P, Krogstad O. Effect of orthodontic treatment on prevalence of Streptococcus mutans in plaque and saliva. Scand J Dent Res. 1984; 92: 211 - 217.

24. Sinclair PM, Berry CW, Bennett CL, Israelson $\mathrm{H}$. Changes in gingiva and gingival flora with bonding and banding. Angle Orthod 1987; 57: $271-278$.

25. Rosenbloom RG, Tinanoff N. Salivary Streptococcus mutans levels in patients before, during, and after orthodontic treatment. Am J Orthod Dentofac Orthop 1991;100: 35 - 37.

26. Türkkahraman H, Sayin MO, Bozkurt FY, Yetkin Z, Kaya S, Onal S. Archwire ligation techniques, microbial colonization, and periodontal status in orthodontically treated patients. Angle Orthod 2005; 75: 231 - 236.
27. Naranjo AA, Triviño Ml, Jaramillo A, Betancourth $\mathrm{M}$, Botero JE. Changes in the subgingival microbiota and periodontal parameters before and 3 months after bracket placement. Am J Orthod Dentofacial Orthop 2006; 130: 17 - 22.

28. Hamp SE, Lundström F, Nyman S. Periodontal conditions in adolescents subjected to multiband orthodontic treatment with controlled oral hygiene. Eur J Orthod 1982; 4: 77 - 86.

29. Anderson GB, Bowden J, Morrison EC, Caffesse RG. Clinical effects of chlorhexidine mouthwashes on patients undergoing orthodontic treatment. Am J Orthod Dentofacial Orthop 1997; 111: 606 - 612.

30. Leif G, Ella Z, Rolf A. Oral hygiene instruction of adults by means of a self-instructional manual. J Clin Periodontol 1981; 8: 165 - 176.

31. Bascones A, Morante S. Antisépticos orales. Revisión de la literatura y perspectiva actual. Av Periodon Implantol 2006; 18: 31 - 59.

32. Olympio KPK, Bardal PAP, de M Bastos JR Buzalaf MAR. Effectiveness of a chlorhexidine dentifrice in orthodontic patients: a randomized-controlled trial. J Clin Periodontol 2006; 33: $421-426$.

33. Sari E, Birinci I. Microbiological evaluation of $0.2 \%$ chlorhexidine gluconate mouthrinse in orthodontic patients. Angle Orthod 2007; 77: 881 - 884.

34. Heintze SD, Jost-Brinkman PP, Loundos J. Effectiveness of three different types of electric toothbrushes compared with a manual technique in orthodontic patients. Am J Orthod Dentofacial Orthop 1996; 110: 630 - 638.

35. Lundström F, Hamp SE, Nyman S. Systematic plaque control in children undergoing long-term orthodontic treatment. Eur J Orthod 1980; 2: 27 - 39. 